\title{
Do Foley Catheters Adequately Drain the Bladder? Evidence from CT Imaging Studies
}

\author{
Svetlana Avulova ${ }^{1}$, Valery J. Li ${ }^{1}$, Johnathan A. Khusid ${ }^{1}$, Woo S. Choi ${ }^{2}$, Jeffrey P. Weiss ${ }^{1,3}$ \\ ${ }^{1}$ Department of Urology, SUNY Downstate College of Medicine, Brooklyn, NY, USA; ${ }^{2}$ Radiology, SUNY \\ Downstate College of Medicine, Brooklyn, NY, USA; ${ }^{3}$ Department of Urology, Weill Cornell Medical \\ College, New York, NY, USA
}

\section{ABSTRACT}

Introduction: The Foley catheter has been widely assumed to be an effective means of draining the bladder. However, recent studies have brought into question its efficacy. The objective of our study is to further assess the adequacy of Foley catheter for complete drainage of the bladder.

Materials and Methods: Consecutive catheterized patients were identified from a retrospective review of contrast enhanced and non-contrast enhanced computed tomographic (CT) abdomen and pelvis studies completed from 7/1/2011-6/30/2012. Residual urine volume (RUV) was measured using $5 \mathrm{~mm}$ axial CT sections as follows: The length (L) and width (W) of the bladder in the section with the greatest cross sectional area was combined with bladder height $(\mathrm{H})$ as determined by multiplanar reformatted images in order to calculate RUV by applying the formula for the volume (V) of a sphere in a cube: $\mathrm{V}=(\varpi / 6)^{*}\left(\mathrm{~L}^{*} \mathrm{~W}^{*} \mathrm{H}\right)$.

Results: RUVs of 167 (mean age 67) consecutively catheterized men $(n=72)$ and women $(\mathrm{n}=95)$ identified by CT abdomen and pelvis studies were calculated. The mean RUV was $13.2 \mathrm{~mL}$ (range: $0.0 \mathrm{~mL}-859.1 \mathrm{~mL}$, standard deviation: $75.9 \mathrm{~mL}$, margin of error at 95\% confidence:11.6 mL). Four (2.4\%) catheterized patients had RUVs of $>50 \mathrm{~mL}$, two of whom had an improperly placed catheter tip noted on their CT-reports.

Conclusions: Previous studies have shown that up to $43 \%$ of catheterized patients had a RUV greater than $50 \mathrm{~mL}$, suggesting inadequacy of bladder drainage via the Foley catheter. Our study indicated that the vast majority of patients with Foley catheters (97.6\%), had adequately drained bladders with volumes of $<50 \mathrm{~mL}$.

\section{ARTICLE INFO}

Key words:

Urinary Catheterization; Tomography, X-Ray Computed; Urinary Bladder

Int Braz J Urol. 2015; 41: 552-5

Submitted for publication:

August 02, 2014

Accepted after revision: December 10, 2014

\section{INTRODUCTION}

The Foley catheter has been a staple of medical care since its inception in 1935 by American urologist Frederic Foley (1). Though there have been modifications in the 80 years since its creation, the Foley catheter has withstood the test of time and is considered an acceptable means for bladder drainage in the appropriate setting. One of the main complications of its use is catheter-associated urinary tract infection (CAUTI).

The prevalence of CAUTI is high, as up to $40 \%$ of catheterized patients in the acute hospital care setting develop CAUTI (2). This, in conjunction with the fact that up to $25 \%$ of patients admitted to hospitals have a urinary catheter placed at some point during their stay highlights the healthcare burden generated by CAUTI (3). Although 
the cost of each CAUTI is estimated to be less than $\$ 600$, the additive cost to hospitals for lack of Medicare and Medicaid reimbursement of a "preventable complication" is considerable $(4,5)$.

For each day that a catheter is in place, 3-7\% of patients may develop a CAUTI (6). By the 30th day of catheterization, the incidence of CAUTI or catheter-associated asymptomatic bacteriuria (CAASB) is almost 100\% (7). Failure to keep the urinary collection bag in a gravity dependent position is the most commonly violated catheter care-related recommendation, and can double the relative risk of developing CAUTI or CAASB (8).

One potentially modifiable factor to impact the incidence of CAUTI is inadequate drainage of the bladder. Stoller et al. suggested that Foley catheters do not consistently and constantly drain urine from the bladder, with $43 \%$ of patients found to have a residual urine volume $>50 \mathrm{~mL}$ (8). A previous study found that clinically asymp tomatic men with a post-void residual volume (PVR) of $>180 \mathrm{~mL}$ are at high risk for developing bacteriuria (9). Further, PVR $>150 \mathrm{~mL}$ in a non-catheterized patient is associated with an increased risk of developing a urinary tract infection (10). Taking these findings together, it would seem logical that we can reduce the incidence of CAUTI by addressing the problem of inadequate bladder drainage by Foley catheters. As such, the purpose of our study was to evaluate the efficacy of the Foley catheter in bladder drainage.

\section{MATERIALS AND METHODS}

After obtaining approval from our Institutional Review Board (approved protocol \#3309371), we retrospectively identified 167 consecutively catheterized patients via contrast enhanced and non-enhanced abdominal and pelvic CT studies from 7/1/2011-6/30/2012. Patients with suprapubic bladder drainage catheters were excluded.

We assessed residual urine volume (RUV) by utilizing the $5 \mathrm{~mm}$ axial section demonstrating the greatest bladder cross sectional area. Using coronal multiplanar reformatted images to determine maximum bladder height, RUV was calculated by means of the formula for the volume (V) of a sphere in a cube with a given length (L), width $(W)$, and height $(H): V=(\pi / 6)^{*}\left(W^{*} L^{*} H\right)$.

\section{RESULTS}

Patients were stratified into three groups: RUV $=0 \quad(\mathrm{n}=68,40.7 \%)$, RUV $>0$ and $<50 \mathrm{~mL}$ $(\mathrm{n}=95,56.9 \%$, mean $=6.7 \mathrm{~mL}$, standard deviation (st dev) $=7.9 \mathrm{~mL})$, and RUV $\geq 50 \mathrm{~mL}(\mathrm{n}=4,2.4 \%$, mean $=394.7 \mathrm{~mL}$, st $\mathrm{dev}=345.3 \mathrm{~mL}$ ). Two of the four patients with RUV $\geq 50 \mathrm{~mL}$ were found to have improperly placed catheters by CT. The overall mean RUV was $13.2 \mathrm{~mL}$ with a st dev of 75.9 $\mathrm{mL}$ and margin of error of $11.6 \mathrm{~mL}$ for a $95 \%$ confidence interval.

We further stratified patients by gender. Thirty nine women (41\%) had RUV $=0 \mathrm{~mL}, 54$ $(57 \%)$ had a RUV $>0 \mathrm{~mL}$ and $<50 \mathrm{~mL}$ (mean $=8.0$ $\mathrm{mL}$, st dev $=8.3 \mathrm{~mL})$, and $2(2 \%)$ had $\mathrm{RUV} \geq 50 \mathrm{~mL}$, (mean=301.4 mL, st dev=172.6 mL). The overall mean RUV for women was $10.9 \mathrm{~mL}$ with a st dev of $50.0 \mathrm{~mL}$. Twenty nine men (40.3\%) had RUV=0 $\mathrm{mL}, 41(57 \%)$ had a residual urine volume of $>0$ $\mathrm{mL}$ and $<50 \mathrm{~mL}$, (mean=4.9 mL, st dev $=7.0 \mathrm{~mL}$ ), and $2(2.8 \%)$ had RUV $>50 \mathrm{~mL}$ (mean=488.1 mL, st dev=362.8 $\mathrm{mL}$ ). The overall mean RUV for men was $16.2 \mathrm{~mL}$, with a st dev of $100.2 \mathrm{~mL}$. A summary of our data analysis is provided in Table- 1 .

\section{DISCUSSION}

Contrary to the study performed by Stoller et al., we found that the vast majority of our patients $(97.6 \%)$ had a RUV of $<50 \mathrm{~mL}$. Further, $40.7 \%$ of our patients were found to have no residual volume at all. This contrast may be attributed to differences in study design. In Stoller's study, bladder sonography was performed at the bedside whereas in the present cohort, the patient was transported to the CT department. It is possible that during transport, manipulation and movement of the Foley, as well as changes in abdominal pressure during transfer resulted in drainage in urine from the bladder. Since patients either move or are turned/moved frequently while in hospital beds, we feel that CT-derived measurement of bladder volume still represents a "real world" situation amongst catheterized inpatients. Further, sonographic measurement of the bladder is less precise when the bladder is collapsed $(11,12)$. 
Table 1 - Summary of Data.

\begin{tabular}{lccc}
\hline Group & $0 \mathrm{~mL}$ & $>0 \mathrm{~mL} \&<50 \mathrm{~mL}$ & $\geq 50 \mathrm{~mL}$ \\
\hline N women & 39 & 54 & 2 \\
\%women & $41.1 \%$ & $56.8 \%$ & $2.1 \%$ \\
Mean/SD Women $(\mathrm{mL})$ & -- & $8.0 / 8.3$ & $301.4 / 172.6$ \\
N men & 29 & 41 & 2 \\
\%men & $40.3 \%$ & $56.9 \%$ & $2.8 \%$ \\
Mean/SD Men $(\mathrm{mL})$ & -- & $4.9 / 7.0$ & $488.1 / 362.8$ \\
N total & 68 & 95 & 4 \\
$\%$ total & $40.7 \%$ & $56.9 \%$ & $2.4 \%$ \\
Mean/SD total $(\mathrm{mL})$ & -- & $6.7 / 7.9$ & $394.7 / 345.3$ \\
\hline
\end{tabular}

$\mathrm{mL}=$ milliliters, $\mathbf{N}=$ number, $\mathbf{S D}=$ standard deviation

In the present study, while only $2 \%$ of patients had a RUV of $>50 \mathrm{~mL}, 59 \%$ of patients a RUV of $>0 \mathrm{~mL}$, indicating that for most patients the Foley catheter does not completely drain the bladder. Though some of the smaller volumes may be considered negligible, $16 \%$ of our patients $(\mathrm{n}=26)$ had a RUV of $>10 \mathrm{~mL}$.

We found that half $(2 / 4)$ of the patients with a RUV $>50 \mathrm{~mL}$ had an improperly placed catheter, emphasizing the importance of catheter placement technique and urine output monitoring. Hence, the vast majority of properly placed catheters appear to drain the bladder at least moderately well with an arbitrary "cut point" of $50 \mathrm{~mL}$. The importance of finite RUV $<50 \mathrm{~mL}$ in catheterized patients has yet to be determined.

\section{CONCLUSIONS}

In summary, our retrospective study provides three principal findings:

1) For the vast majority of patients the Foley catheter adequately drained the bladder;

2) There were no gender differences in the efficacy of the Foley catheter in bladder drainage;

3) Improper placement of a Foley catheter can lead to significant urinary retention.

\section{ABBREVIATIONS}

CAUTI $=$ catheter-associated urinary tract infection
CAASB $=$ catheter-associated asymptomatic bacteriuria

PVR $=$ post-void residual volume

RUV = residual urine volume

$\mathrm{L}=$ length

$\mathrm{W}=$ width

$\mathrm{H}=$ height

$\mathrm{V}=$ volume

St $\mathrm{dev}=$ standard deviation

\section{CONFLICT OF INTEREST}

None declared.

\section{REFERENCES}

1. Carr HA. A short history of the Foley catheter: from handmade instrument to infection-prevention device. J Endourol. 2000; 14:5-8.

2. National Nosocomial Infections Surveillance System. National Nosocomial Infections Surveillance (NNIS) System Report, data summary from January 1992 through June 2004, issued October 2004. Am J Infect Control. 2004; 32:470-85.

3. Weinstein JW, Mazon D, Pantelick E, Reagan-Cirincione P, Dembry LM, Hierholzer WJ Jr. A decade of prevalence surveys in a tertiary-care center: trends in nosocomial infection rates, device utilization, and patient acuity. Infect Control Hosp Epidemiol. 1999; 20:543-8.

4. Tambyah PA, Knasinski V, Maki DG. The direct costs of nosocomial catheter-associated urinary tract infection in the era of managed care. Infect Control Hosp Epidemiol. 2002; 23:27-31. 
5. Saint S, Meddings JA, Calfee D, Kowalski CP, Krein SL. Catheter-associated urinary tract infection and the Medicare rule changes. Ann Intern Med. 2009; 150:877-84.

6. Nicolle LE. Catheter-related urinary tract infection. Drugs Aging. 2005; 22:627-39.

7. Maki DG, Tambyah PA. Engineering out the risk for infection with urinary catheters. Emerg Infect Dis. 2001; 7:342-7.

8. Garcia MM, Gulati S, Liepmann D, Stackhouse GB, Greene K, Stoller ML. Traditional Foley drainage systems--do they drain the bladder? J Urol. 2007; 177:203-7; discussion 207.

9. Truzzi JC, Almeida FM, Nunes EC, Sadi MV. Residual urinary volume and urinary tract infection--when are they linked? J Urol. 2008; 180:182-5.

10. Dromerick AW, Edwards DF. Relation of postvoid residual to urinary tract infection during stroke rehabilitation. Arch Phys Med Rehabil. 2003; 84:1369-72.
11. Hakenberg OW, Ryall RL, Langlois SL, Marshall VR. The estimation of bladder volume by sonocystography. J Urol. 1983; 130:249-51.

12. Simforoosh N, Dadkhah F, Hosseini SY, Asgari MA, Nasseri A, Safarinejad MR. Accuracy of residual urine measurement in men: comparison between real-time ultrasonography and catheterization. J Urol. 1997; 158:59-61.

Correspondence address: Johnathan Alexander Khusid, MD Department of Urology, SUNY Downstate 450 Clarkson Avenue Brooklyn, NY 11203, USA Fax: +1 718 270-3848

E-mail: johnathan.khusid@downstate.edu 